
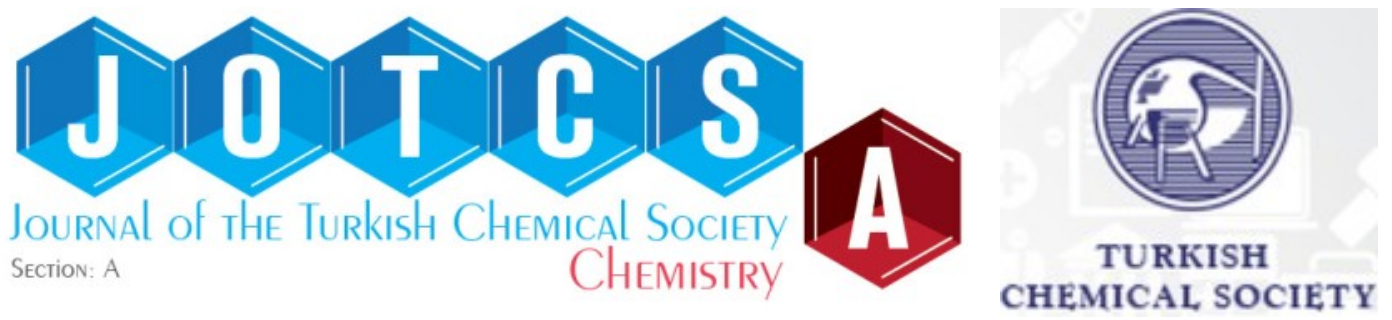

\title{
Voltammetric and spectrophotometric pathways for the determination of total antioxidant capacity in commercial turnip juice
}

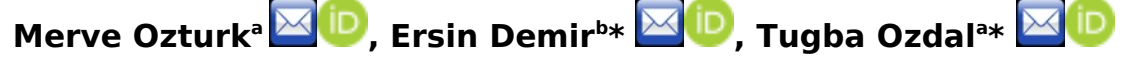

${ }^{a}$ Department of Food Engineering, Faculty of Engineering, Istanbul Okan University, Istanbul, 34959, Turkey

${ }^{b}$ Afyonkarahisar Health Sciences University, Faculty of Pharmacy, Department of Analytical Chemistry, 03030, Afyonkarahisar, Turkey

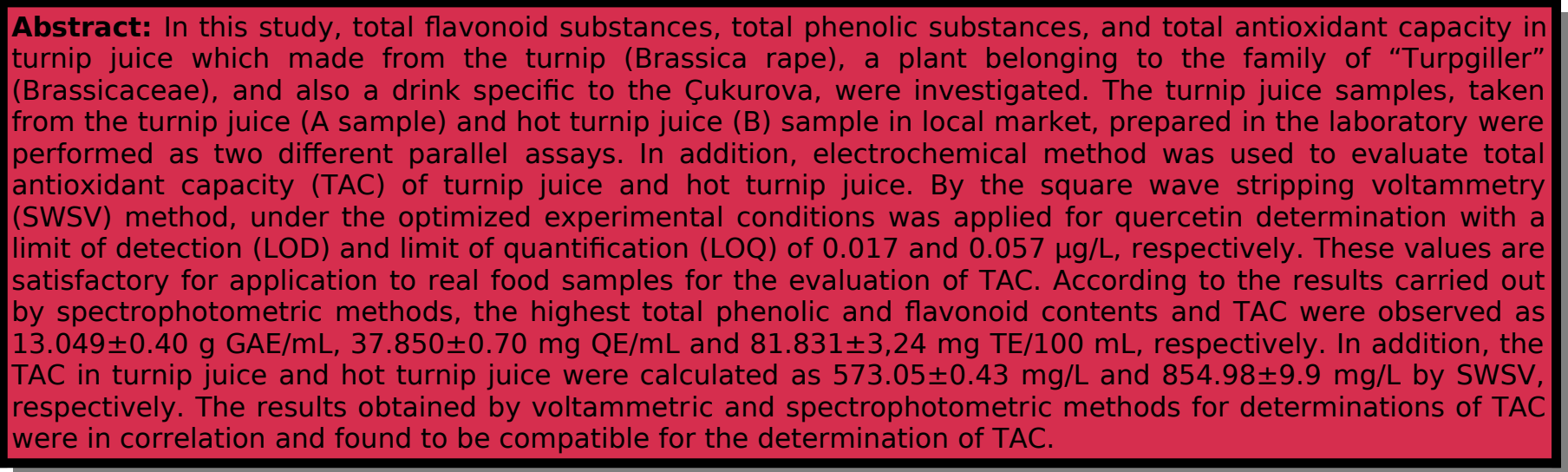

Keywords: Antioxidant; Turnip juice, Voltammetry, Spectrophotometry

Submitted: June 15, 2020. Accepted: December 15, 2020.

Cite this: Ozturk M, Demir E, Ozdal T. Voltammetric and spectrophotometric pathways for the determination of total antioxidant capacity in commercial turnip juice. JOTCSA. 2021;8(1):163-72.

DOI: https://doi.org/10.18596/jotcsa.752982.

* Corresponding authors: Email: ersindemir@aku.edu.tr; tugba.ozdal@okan.edu.tr

\section{INTRODUCTION}

Antioxidants can be classified mainly in two groups, primary and chain-breaking. In addition, it can be divided into 5 groups as primary antioxidants, secondary antioxidants, enzymatic antioxidants, oxygen cleaners and chelating agents (1). Phenolic compounds directly contribute to the antioxidant capacity amount in foods (2). The most important effect of antioxidant compounds on human health inhibits the damage caused by free radicals in the body or prevents complete damage. The source of free radicals (unpaired electrons) can be events such as prolonged exposure to X-rays, excessive smoking, intensely polluted air, and exposure to toxic industrial chemicals (3). It is recommended to consume food products with high antioxidant capacity against diseases such as cancer, cardiovascular disease, carcinogenesis, aging and Alzheimer's caused by free radicals $(3,4)$.

Turnip juice is produced from the turnip (Brassica rape), a plant belonging to the family of Brassicaceae. Turnip juice consumption is very common in Turkey 
although it is a drink specific to the Cukurova province. Although there are some differences in its production, purple carrots, radishes, bulgur flour, sour dough, salt, water and red powdered pepper are used in making turnip juice (5). Generally, two methods are dominant for the production of turnip juice. The first is the traditional method and the other is the direct method, which can vary locally (6). Turnip juice is a functional beverage with a very strong antioxidant activity due to its rich phenolic and anthocyanin content. Functional properties of turnip juice can be listed as cleaning the respiratory tract, regulating the digestive system, preventing cardiac and vascular diseases, and influencing the immune system in a positive direction (7). In turnip juice, the color comes from the black carrot, rich in phenolic content of the anthocyanins. During turnip juice fermentation lactic acid fermentation takes place that make a great influence on taste and odor characteristics of the product.

Turnip is one of the most effective antioxidant substances against cutaneous diseases thanks to its abundant vitamin $C$ content. Turnip juice can also support the immune system by increasing blood cell function due to its rich content. Moreover, it inhibits free radicals caused blockages. It can also reduce the severity and duration of the common cold by reducing histamine levels. Thanks to glucosinolates, another important ingredient in turnip juice, it plays an important role in cancer treatment. Carrot, which is one of the raw materials of turnip juice, is an excellent source of antioxidants due to its abundant phenolic content, flavonoids and pro-vitamins. They detected abundant purple pigments and Cyanidine-3-glucoside derivatives, which can exhibit abundant purple pigments and chemopreventive and chemotherapeutic activity (8). Furthermore, purple carrots are known to contain more antioxidant, vitamin, carotenoid and phenolic compounds than colored carrot varieties such as orange, yellow and white (9). In conclusion, it is very important to investigate the amount of antioxidants of turnip juices, which is an important and natural drink for human health.

The various methods have been used to measure the in vitro antioxidant capacities of fruits and vegetables in the literature. Methods such as cupric ion reducing antioxidant capacity (CUPRAC) and 2,2diphenyl-1-picrylhydrazyl (DPPH) are simple, costeffective, easily interpreted and show either reduction capacity (CUPRAC) or direct free radical inhibition (DPPH) (10). While evaluating antioxidant capacity of a food or beverage, at least two of these assays should be combined to have a more reliable conclusion of the total antioxidant capacity (11). Furthermore, in routine antioxidant analyses, cheap, fast, sensitive, environmentally friendly, and reliable new methods are needed. Electrochemical measurements draw great attention in this respect, especially since they are cheap, reliable, and environmentally friendly. Therefore, antioxidant studies with electrochemical methods have been concentrated in the last decade.

In this study, total antioxidant capacities (TAC) in commercial turnip juices were evaluated by voltammetric and spectrophotometric methods. In order to compare with the voltammetric and traditional analytical methods for the TAC, quercetin was chosen as a reference standard substance. Moreover, gallic acid, quercetin, and trolox were used to investigate for the total phenolic content analysis, total flavonoid analysis and total antioxidant capacities in spectrophotometric methods, respectively. In the electrochemical study, square wave stripping voltammetry (SWSV) was used under the optimum experimental conditions such as $\mathrm{pH}$ medium, accumulation time, frequency, and step potential, etc. were researched on carbon paste electrode (CPE). Thus, TAC values obtained by different methods were evaluated statistically. Consequently, TAC values of turnip juices were analyzed for the first time using both electrochemical and conventional analytical methods.

\section{EXPERIMENTAL}

\section{Electrochemical Instrumentation}

For the electrochemical measurements, Gamry Reference 600 Electrochemical Analyzer was used. The analyzer consists of triple electrode systems which is a platinum wire, a $\mathrm{Ag} / \mathrm{AgCl}$ reference electrode and carbon paste electrode (CPE) (BASi MF 2010; Ø $3 \mathrm{~mm}$, diameter) as working electrode. In addition, a voltammetric cell with $10 \mathrm{~mL}$ capacity was used for collecting the voltammetric data. The working electrode was performed using carbon nanotube powder (MER Corporation, mesh size $<53 \mu \mathrm{m}$ ) and mineral oil at a mass ratio of $70 \%$ and $30 \%$, respectively. The carbon paste powder was plugged into the hollow part of the BASi MF 2010 electrode attached. After that, the electrode surface was polished on a polishing cloth. The $\mathrm{pH}$ measurements were performed by digital a $\mathrm{pH}$ meter (Mettler Toledo, S220).

\section{Reagents and solutions}

The analytical standard of quercetin ( $\geq 98.0 \%)$ was purchased from Sigma-Aldrich. A 500 ppm stock solution of quercetin was prepared daily by dissolving it in water. All other reagents were provided analytical grade and used without further purification. $0.04 \mathrm{M}$ Britton-Robinson ( $B-R$ ) solutions were used as a supporting electrolyte by mixing of $2.7 \mathrm{~mL}$ of orthophosphoric, $2.5 \mathrm{~g}$ of boric, and $2.3 \mathrm{~mL}$ of acetic acids in distilled water. B-R buffer solutions were 
prepared from $\mathrm{pH} 2.0$ to 10.0 by adding the required amount of $5 \mathrm{M} \mathrm{NaOH}$ in this triple acid mixture and monitoring with a $\mathrm{pH}$ meter. All stock solutions were stored in a refrigerator at $4.0^{\circ} \mathrm{C}$. All electrochemical data were carried out at a comfortable ambient temperature $25 \pm 2{ }^{\circ} \mathrm{C}$.

\section{Food samples assay procedure}

The commercial turnip juice samples were purchased from a local market. $0.1 \mathrm{~mL}$ of the real sample solution was directly placed into $10.0 \mathrm{~mL}$ of $\mathrm{pH} 7.0 \mathrm{~B}-\mathrm{R}$ buffer solution without any purification and pretreatment food samples. Then, the SWSV measurements from - 0.2 to $1.3 \mathrm{~V}$ were obtained to determine the antioxidant capacity of food samples under optimum conditions (step potential $\left(E_{s}\right) 3 \mathrm{mV}$; frequency $(f) 300 \mathrm{~Hz}$; pulse amplitude $(E) 110 \mathrm{mV}$; accumulation potential $\left(E_{a c c}\right) 200 \mathrm{mV}$; accumulation time $\left(t_{a c c}\right) 30 \mathrm{~s}$ and $\mathrm{pH} 7.0 \mathrm{~B}-\mathrm{R}$ buffer solutions). For all the food samples, the measurements were performed in triplicate and the validation parameters were calculated.

\section{Spectrophotometric Methods}

Two types of turnip juice (hot turnip juice and basic turnip juice) were purchased from local market. According to the results of 1,1-diphenyl-2picrylhydrazyl (DPPH) and cupric reducing antioxidant capacity (CUPRAC) methods, total phenolics, total flavonoids, and antioxidant capacities in turnip juice samples were determined.

\section{Sample preparation}

Two different turnip juice samples (hot and basic) were diluted $1 / 10$ and $1 / 100$ using $80 \%$ methanol and samples were subjected to vortex mixer for 30 seconds in sterile sample containers and then stored in a refrigerator at $-18{ }^{\circ} \mathrm{C}$. Examples in the research were carried out by spectrophotometry in the food engineering laboratory of Okan University.

\section{Determination of total phenolic content}

Total phenolics determination was performed colorimetrically as developed slightly by Shahidi and Naczk (12). For this, Folin-Ciocalteu's phenol reagent and gallic acid solutions were prepared with $7.5 \%$ $\mathrm{Na}_{2} \mathrm{CO}_{3}$ in milli-Q water and distilled water, respectively. The phenol reagent of Folin-Ciocalteu was kept in the dark when not in use. $50 \mu \mathrm{L}$ of diluted phenolic extract, in $1.5 \mathrm{~mL}$ of $7.5 \%$ sodium carbonate solution and $1.5 \mathrm{~mL}$ of Folin-Ciocalteu's Phenol Reagent was homogeneously mixed with vortex in test tubes. A standard calibration graph was created for gallic acid at a concentration of 0.01 to $0.8 \mathrm{~g} / \mathrm{L}$ in $80 \%$ methanolic solution. Absorbance measurements were obtained at $765 \mathrm{~nm}$ using the Beckman Coulter DU 730 Life Science UV/Vis Spectrophotometer. The measured blank solution's absorbance was removed from the absorbance of the sample and standard substances. The measurements taken for each turnip juice sample were repeated three times. As a result, the content of phenolics was calculated as mg gallic acid equivalent (GAE)/100 g of dry weight.

\section{Determination of total flavonoid content}

Total flavonoids in turnip juice were measured colorimetrically as described by Dewanto et al. (2002), Zhishen et al. (1999) and Lee et al. (2003) (13-15). Firstly, stock solutions such as $5 \%$ sodium nitrite $\left(\mathrm{NaNO}_{2}\right), 1 \mathrm{M}$ sodium hydroxide $(\mathrm{NaOH}), \quad 10 \%$ aluminum chloride hexahydrate $\left(\mathrm{AlCl}_{3} .6 \mathrm{H}_{2} \mathrm{O}\right)$ and quercetin $(1 \mathrm{~g} / \mathrm{L})$ were prepared very precisely. $1 \mathrm{~mL}$ of diluted turnip sample was mixed with $0.3 \mathrm{~mL}$ of $5 \%$ $\mathrm{NaNO}_{2}$. Then $0.6 \mathrm{~mL}$ of $10 \% \mathrm{AlCl}_{3} \cdot 6 \mathrm{H}_{2} \mathrm{O}$ and $2 \mathrm{~mL}$ of 1 $\mathrm{M} \mathrm{NaOH}$ were added. Finally, $2.4 \mathrm{~mL}$ of water was added quickly and vortexed immediately. Calibration graphic for quercetin was created in different concentrations between $0.01 \mathrm{~g} / \mathrm{L}$ and $0.8 \mathrm{~g} / \mathrm{L}$ in $80 \%$ methanolic solution. Absorbance data were obtained in $80 \%$ methanol solution at $510 \mathrm{~nm}$ using Shimadzu UV-1700 Pharmospec UV-Visible Spectrophotometer and all analyses were also performed in triplicate. The content of flavonoids in turnip juices was calculated as $\mathrm{mg}$ quercetin/100 $\mathrm{mL}$ sample.

\section{Determination of antioxidant capacity according to DPPH method}

For the amount of antioxidant in turnip juices, colorimetric method was used as described by Kumaran (2006) and Rai et al. (2006) (16, 17). $1 \mathrm{mM}$ DPPH solution was prepared from methanol. The absorbances of turnip juice samples were collected against the methanol blank solution at $517 \mathrm{~nm}$ using Shimadzu UV-1700 Pharmospec UV-Visible Spectrophotometer. The calibration plot for Trolox was obtained between $0.01 \mathrm{~g} / \mathrm{L}$ and $0.8 \mathrm{~g} / \mathrm{L}$ in $80 \%$ methanol solution. All analyses were performed three times for each turnip sample, and the results were calculated in mg Trolox equivalent (TEAC).

\section{Determination of antioxidant capacity according to CUPRAC method}

Antioxidant capacities of turnip juice samples were analyzed colorimetrically by CUPRAC method developed by Apak et al. (2004) (18). In the first stage of the study, solutions of copper (II) chloride at a concentration of $0.01 \mathrm{M}$, neocuproine $(\mathrm{Nc})$ in ethanol at a concentration of $7.5 \times 10^{-3} \mathrm{M}$, and ammonium acetate $\left(\mathrm{NH}_{4} \mathrm{Ac}\right)$ buffer at $\mathrm{pH} 7.0$ was prepared very precisely. Moreover, the solutions used in the whole experiment were prepared daily. $1 \mathrm{~mL}$ of copper (II) chloride solution, $1 \mathrm{~mL}$ of ammonium acetate buffer and $1 \mathrm{~mL}$ of neocuproine were added to $100 \mu \mathrm{L}$ of the turnip samples. Absorbance data were obtained in $80 \%$ methanol solution at $450 \mathrm{~nm}$ using Shimadzu UV1700 Pharmospec UV-Visible Spectrophotometer and all analyses were performed in triplicate. Calibration graph for Trolox was created in different 
concentrations between 0.01 and $0.8 \mathrm{~g} / \mathrm{L}$ in $80 \%$ methanol solution. All analyses were performed in triplicate for each turnip sample, and the results were calculated in mg trolox equivalent (TEAC).

\section{Statistical Analysis}

Student's t-test was performed to understand if there are statistically significant $(p<0.05)$ differences between total flavonoid contents and total phenolics, total antioxidant capacities of two turnip juice samples in spectrophotometric method. Electrochemical analysis results for total antioxidant capacities in turnip juice samples were obtained on the standard calibration chart. Results were calculated as mean and standard deviation.

\section{RESULTS AND DISCUSSION}

\section{Electrochemical Analysis}

In analytical chemistry, electrochemical methods are used for investigating a huge scale of substances. For example, metal ions and organic compounds are discovered in pesticides, food, and medicine. They are generally quick and cheap. The using of electrochemical methods, investigations of antioxidant in in food sources have been analyzed by some groups (19-23). Cyclic voltammetry (CV) and differential pulse voltammetry (DPV) and square wave voltammetry (SWV) have been mostly used for electrochemical species, because the results give very fast and reliable results in total antioxidant capacity (TAC) analysis (24-26). It is imaginable to have quantitative analysis of antioxidant present in the samples. The different groups of antioxidants compound such as phenolics and ascorbic acid show different oxidation potential which shows the results in different regions of antioxidants, a mignon number of electrochemical methods can be discovered in the literature.

\section{Optimization of the Parameters}

The influence of step potential $\left(E_{s}\right)$ was studied by step potentials from $1 \mathrm{mV}$ to $6 \mathrm{mV}$. The peak current increased at between $1 \mathrm{mV}$ and $3 \mathrm{mV}$ and then it shows stability after $3 \mathrm{mV}$ for step potentials. Hence, $3 \mathrm{mV}$ was chosen as the optimum step potential for the subsequent experiments. The effect of pulse amplitude $(E)$ was also determined various amplitudes from $10 \mathrm{mV}$ to $110 \mathrm{mV}$. The oxidation peak signal increased until $90 \mathrm{mV}$ linearly. That is why $110 \mathrm{mV}$ was chosen as the optimum pulse amplitude because the maximum result is obtained from from $110 \mathrm{mV}$. In addition to these steps, accumulation time $\left(t_{\text {acc }}\right)$ was determined from $10 \mathrm{~s}$ to $70 \mathrm{~s}$. Until $30 \mathrm{~s}$, the oxidation peak current was increased. After this point, accumulation time was not depended on peak current of quercetin because electrode surface is saturated fully. Therefore, optimum accumulation time was chosen as $30 \mathrm{~s}$. The next step is accumulation potential $\left(E_{\text {acc }}\right)$ was studied from $100 \mathrm{mV}$ to $600 \mathrm{mV}$. The increase of peak current started at $100 \mathrm{mV}$ and after $200 \mathrm{mV}$, it showed stability until $600 \mathrm{mV}$. The available accumulation potential is $200 \mathrm{mV}$. The impact of frequency $(f)$ was evaluated between $20 \mathrm{~Hz}$ and $300 \mathrm{~Hz}$. The peak current gradually increased between 20 and $300 \mathrm{~Hz}$. Therefore, the optimum frequency was used as a $300 \mathrm{~Hz}$ at subsequent measurements. The optimized parameters for the SWSV in $1 \mathrm{mg} / \mathrm{L}$ quercetin were shown in Figure 1 and Table 1.

Table 1. Optimized parameters of SWSV for the determination of quercetin.

\begin{tabular}{l} 
Parameters \\
\hline Step potential $\left(E_{s}\right)$ \\
Pulse amplitude $(E)$ \\
Accumulation potential $\left(E_{a c c}\right)$ \\
Accumulation time $\left(t_{a c c}\right)$ \\
Frequency $(f)$ \\
Supporting electrolyte \\
Peak Potential
\end{tabular}

Optimized values/unit

$3 \mathrm{mV}$

$110 \mathrm{mV}$

$200 \mathrm{mV}$

$30 \mathrm{~s}$

$300 \mathrm{~Hz}$

pH 7.0 B-R Buffer solution $+200 \mathrm{mV}$ 


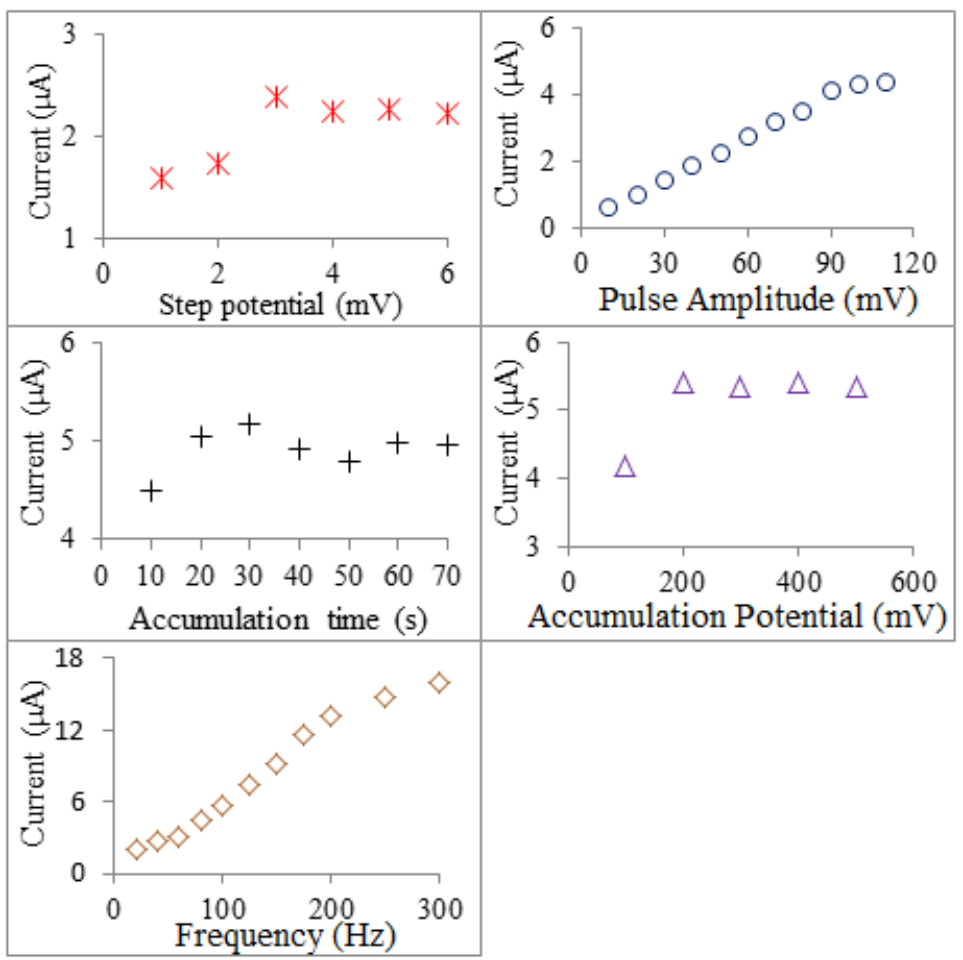

Figure 1. Optimized parameters for the SWSV in $1 \mathrm{mg} / \mathrm{L}$ quercetin.

\section{Influence of pH}

In the electrochemical studies, supporting electrolyte is one of most important parameters due to the effects on peak potential, current intensity can also affect the electrode kinetics in the charge transfer process. Hence, the effects of the supporting electrolyte anodic signal of quercetin at various $\mathrm{pH}$ values on the carbon paste electrode (CPE) were investigated. In order to determine the $\mathrm{pH}$ effect, square wave stripping (SWS) voltammograms were taken in the Britton-Robinson buffer solutions between $\mathrm{pH} 2.0$ and $\mathrm{pH} 10.0$ for the $1 \mathrm{mg} / \mathrm{L}$ quercetin. SWS experiments that the highest signals were obtained in moderate medium at $\mathrm{pH} 7.0$ were found to be dependent on the below $\mathrm{pH} \leq 10.00$ buffer solutions. In addition, the oxidation peak potential of quercetin gradually increased linearly between potential from $\mathrm{pH} 3$ to $\mathrm{pH} 7$ per unit $\mathrm{pH}$ changes. Significant decreasing in the quercetin peak current of quercetin was observed $\mathrm{pH} 7.0$ then to up $\mathrm{pH}$ 10.0. Also, peak potential of the quercetin was a change as $65.28 \mathrm{mV}$ by increasing as unit $\mathrm{pH}$. This is the evidence that consumption of hydrogen ions contains in the electrochemical oxidation process. Britton-Robinson buffer solution at $\mathrm{pH} 7.0$, where maximum peak flow was obtained for the determination of quercetin on the CPE, was determined as the ideal support electrolyte. Figure 2 shows the influence of $\mathrm{pH}$ for the peak I. (1 mg/L of quercetin from $\mathrm{pH} 2.0$ to $\mathrm{pH} 10.0$ )

$$
\mathrm{Ep}(\mathrm{mV})=-65.28 \mathrm{pH}+635.97(\mathrm{mV})\left(\mathrm{R}^{2}=0.9919\right)
$$

$\mathrm{Ep}(\mathrm{mV})=-50.85 \mathrm{pH}+990.6(\mathrm{mV})\left(\mathrm{R}^{2}=0.9996\right)$ 


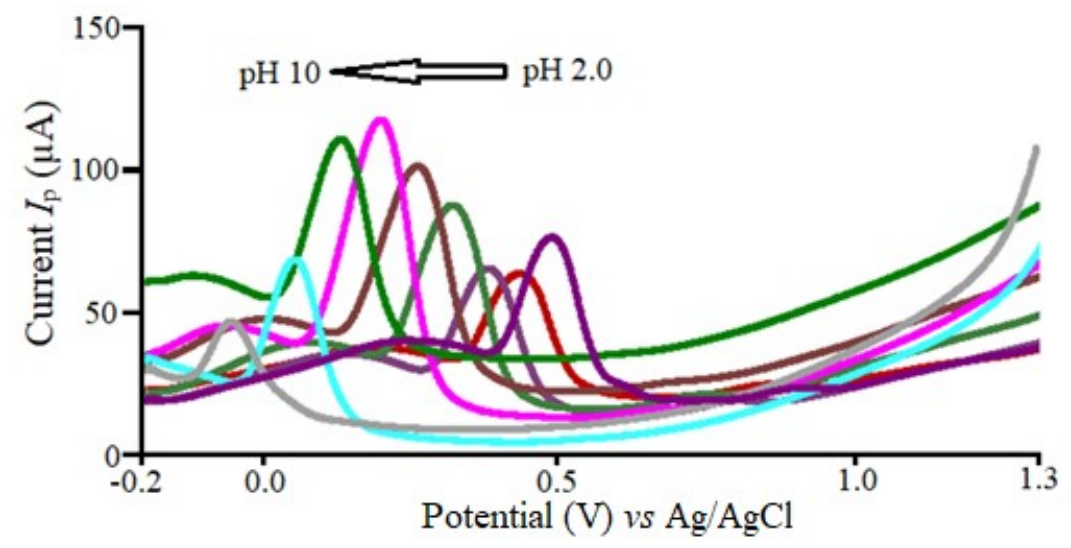

Figure 2. The $\mathrm{pH}$ effects on the peak I in $1 \mathrm{mg} / \mathrm{L}$ of quercetin by SWSV.

\begin{abstract}
Quantitative evaluation and validation of $\mu \mathrm{g} / \mathrm{L}$ and $0.057 \mu \mathrm{g} / \mathrm{L}$, respectively. In calculating LOD Quercetin

Peak current values against concentration were evaluated for anodic peak I of quercetin by using CPE. The peak intensities changed in a way to increase linearly as a result of increasing quercetin concentrations by SWSV on CPE in pH 7.0 (Figure 3). As a result of this change, a linear working range and $L O Q$ values, $L O D=3 \mathrm{~s} / \mathrm{m}$ and $L O Q=10 \mathrm{~s} / \mathrm{m}$ equations were preferred. The " $\mathrm{m}$ " is the slope of the calibration equation of the quercetin and the " $s$ " is the standard deviation of the point where the concentration in the calibration equation is zero. Validation parameters of the calibration chart for quercetin determination are summarized in Table 2.
\end{abstract} between $0.04 \mu \mathrm{g} / \mathrm{L}$ and $10 \mu \mathrm{g} / \mathrm{L}$ was obtained on the calibration graph. The limit of determination (LOD) and limit of detection (LOQ) were calculated as 0.017

$$
I p(\mu \mathrm{A})=0.203(\mathrm{C}, \mu \mathrm{g} / \mathrm{L})-0.032 r=0.9934
$$

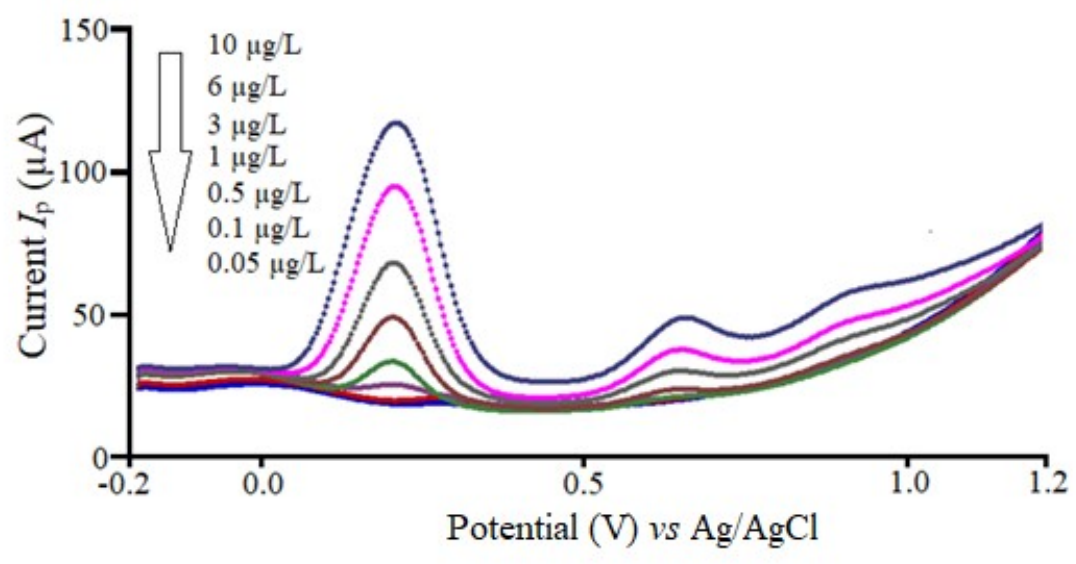

Figure 3. SWS voltammograms for the calibration graph of quercetin on $\mathrm{CPE}$ in $\mathrm{pH}$ 7.0.

Table 2.Validation parameters for determination of quercetin by SWS on CPE.

\begin{tabular}{lc}
\hline Parameter & Value \\
\hline Peak potential $\left(\mathrm{E}_{\mathrm{p}}\right)(\mathrm{mV})$ & +200 \\
Working range $(\mu \mathrm{g} / \mathrm{L})$ & $0.04-10.0$ \\
Slope $(\mu \mathrm{A} \mathrm{L} / \mu \mathrm{g})$ & 0.203 \\
Intercept $(\mu \mathrm{A})$ & -0.032 \\
Limit of determination $(\mathrm{LOD})(\mu \mathrm{g} / \mathrm{L})$ & 0.017 \\
Limit of detection $(\mathrm{LOQ})(\mu \mathrm{g} / \mathrm{L})$ & 0.057 \\
Correlation coefficient & 0.9934 \\
\hline
\end{tabular}


The determination TAC in turnip juices on CPE by SWSV

With the increasing importance of antioxidant substances in recent years, scientists are researching new analytical methods for antioxidant capacity determinations. A standard method for the determination of antioxidants, especially in complex samples such as food, has not yet been fully developed. Analytical methods such as chromatography, spectrophotometry, capillary electrophoresis, and spectrofluorometric analyses have been widely preferred in determining antioxidant capacity. However, the working principles of these methods are very different from each other. The common problems of these methods are them being expensive, analysis times are long and they are using too many chemicals. In addition, using less organic solvent is an important indicator for environmentally friendly methods. For these reasons, electrochemical methods, which are a fast, cheap, and reliable method that require less solution, are of great interest in antioxidant determinations. Furthermore, electrochemical methods are included not only in the determination of antioxidants, but also in the analysis of many different substances such as drugs, pesticides, metals, vitamins and amino acids.

In this study, the total antioxidant capacity of turnip juices purchased from the local market was examined for the first time with a CPE using quercetin as the reference compound. Firstly, turnip juice samples were diluted 10 times with methanol and analyzed directly by SWSV method in buffer solutions at pH 7.0. SWS voltammograms were obtained in turnip samples under the optimization conditions for standard quercetin solutions. Then, by adding standard quercetin as a $0.5 \mu \mathrm{g} / \mathrm{L}$ in the turnip juice samples, the total antioxidant capacity was calculated as equivalent quercetin from the peak current increase. Figures $4 \mathrm{a}$ and $4 \mathrm{~b}$ represent the electrochemical analysis on carbon paste electrode for the total antioxidant capacity of turnip juice as sample $A$ and sample B by SWSV, respectively determination of the total antioxidant capacity in turnip juices with SWSV is given in Table 3. Consequently, TAC values found by electrochemical method are mostly compatible with the results of total flavonoid contents.

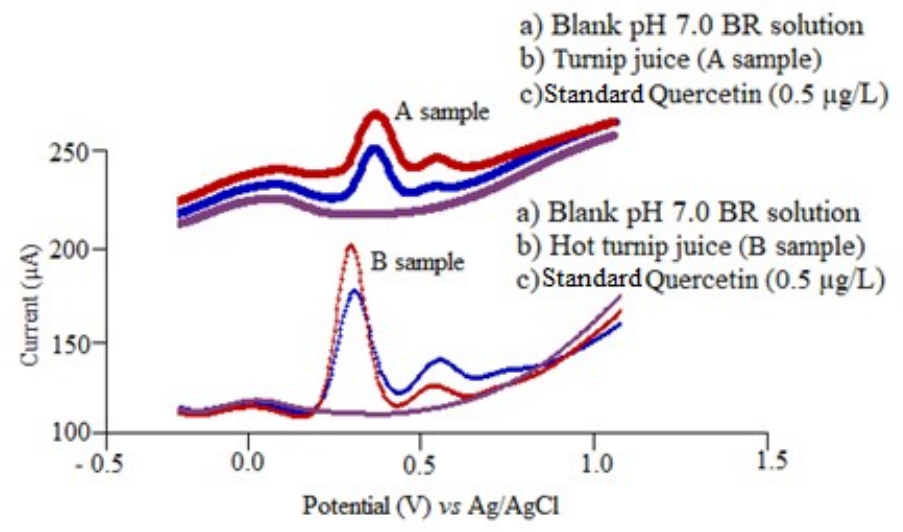

Figure 5. Electrochemical determination pathway of total antioxidant capacity for the turnip juice samples by SWSV on carbon paste electrode.

Table 3. The determination of the total antioxidants capacity (TAC) for the turnip juices by SWSV on carbon paste electrode.

\begin{tabular}{ccc}
\hline Sample & $\begin{array}{c}\text { Total antioxidant capacity } \\
\text { Equivalent Quercetin }\end{array}$ & RDS,\% \\
\hline A & $573 \pm 0.43 \mathrm{mg} / \mathrm{L}$ & 0.07 \\
B & $854 \pm 9.90 \mathrm{mg} / \mathrm{L}$ & 1.16 \\
\hline
\end{tabular}

\section{Spectrophotometric Analysis}

\section{Total Phenolic and Flavonoid Contents}

The concentrations of phenolic compounds in a sample can vary. In addition, phenolic compounds are very rare to be found in the samples in free form. It is generally more likely to exist in the form of glycosides or ester forms with carboxylic acid. Moreover, there is a possibility that phenolic compounds bind to fatty acids, sterols and cellular walls. The amount of total phenolic of sample $A$ and sample $B$ were found as $11.361 \pm 0.49 \mathrm{mg} \mathrm{GAE} / \mathrm{mL}$ and $13.049 \pm 0.40 \mathrm{mg}$ $\mathrm{GAE} / \mathrm{mL}$, respectively (Table 4). According to the results of the total phenolic content, it was determined that the total phenolic content in the $\mathrm{B}$ sample as hot turnip juice was higher than the A sample as turnip juice. Moreover, the total flavonoid 
content of sample B $(37.850 \pm 0.70 \mathrm{mg} \mathrm{QE} / \mathrm{mL}$ turnip juice) was also found to be higher than sample $A$ (23.894 $\pm 0.55 \mathrm{mg} \mathrm{QE} / \mathrm{mL}$ turnip juice) about $58.41 \%$ as shown in Table 4. Furthermore, the total flavonoid content in turnip samples was very close to the electrochemical results in percent. Compared to sample A with electrochemical methods, there was 49.04 percent increase in sample $B$, while this ratio was 58.41 percent with total flavonoid content.

Table 4. The total phenolic and flavonoid contents of turnip juice samples.

\begin{tabular}{lcc}
\hline Sample & $\begin{array}{c}\text { Total Phenolic Contents } \\
\text { (mg GAE/mL turnip juice) }\end{array}$ & $\begin{array}{c}\text { Total Flavanoid Contents } \\
\text { (mg QE/mL turnip juice) }\end{array}$ \\
\hline A (Turnip Juice) & $11.361 \pm 0.49^{\mathrm{a}}$ & $23.894 \pm 0.55^{\mathrm{a}}$ \\
B (Hot Turnip Juice) & $13.049 \pm 0.40^{\mathrm{a}}$ & $37.850 \pm 0.70^{\mathrm{a}}$ \\
\hline
\end{tabular}

In the study of Ekinci et al. (2016), the total phenolic content of turnip juice was found as $0.000517 \pm 0.072$ $\mathrm{mg} \mathrm{GAE} / \mathrm{mL}$ (27). Our results for total phenolic content were higher than their result. However, Öztan (2006) was found the total phenolic content of turnip juice as $15.5 \mathrm{mg} \mathrm{GA} / \mathrm{mL}$ which is in accordance with our results (28).

\section{Antioxidant capacity according to DPPH and CUPRAC Analyses}

The antioxidant activity of turnip juice samples were investigated as TE (mg TE/g $\mathrm{mL}$ ) by DPPH and CUPRAC methods. The antioxidant activity in sample B was higher than those of sample A using both methods. Antioxidant activities in turnip juice and hot turnip juice were found as $57.634 \pm 3.01 \mathrm{mg}$ TE $/ 100 \mathrm{~mL}$ and $81.831 \pm 3.24 \mathrm{mg}$ TE $/ 100 \mathrm{~mL}$, respectively by the DPPH assay (Table 5). On the other hand, antioxidant activity of turnip juice samples were found as $561.18 \pm 45.72 \mathrm{mg}$ TE / $100 \mathrm{~mL}$ for sample $A$ and $619.94 \pm 186.58 \mathrm{mg}$ TE $/ 100 \mathrm{~mL}$ for sample $B$ by CUPRAC analysis (Table 5).

Table 5. Antioxidant capacities of turnip juice samples according to DPPH and CUPRAC analyses.

\begin{tabular}{lcc}
\multicolumn{1}{c}{ Sample } & DPPH & CUPRAC \\
A (Turnip Juice) & (mg TE/100 $\mathbf{~}$ L turnip juice) & (mg TE/100 mL turnip juice) \\
B (Hot Turnip Juice) & $57.634 \pm 3.01^{\mathrm{b}}$ & $561.18 \pm 45.72^{\mathrm{a}}$ \\
\hline
\end{tabular}

\section{Statistical Analysis}

According to $t$-test, $t$ values were found to be 0.438 and 1.238 for total phenolic and total flavonoid analyses, respectively. Therefore, there were no statistically significant difference between two turnip juice samples according to their total phenolic and flavanoid contents. However, there were statistically significant differences between amounts of antioxidant of two samples according to DPPH analysis $(p<0.05)$ as $t$ value was found to be 0.0003 . There were no statistically significant differences (tvalue $=0.312 ; \quad p>0.05$ ) between two samples according to their antioxidant capacities measured by CUPRAC analysis.

\section{CONCLUSION}

Herein, flavonoid contents, phenolic contents, and total antioxidant capacities in turnip juices were investigated. Since the above methods are different from each other in terms of analysis principles and reaction conditions, a single method is not sufficient to show all antioxidant properties. For this reason, this study compared the four most commonly used spectrophotometric tests. The highest phenolic and flavonoid components and antioxidant activities were obtained from hot turnip juice (B sample). This study was carried out by electrochemical analysis except for spectrophotometric tests. A sensitive SWSV method was applied using the carbon paste electrode for the direct development of total antioxidant capacity (TAC) in turnip juices. Using the SWSV method developed for standard quercetin as antioxidant agent determine the total antioxidant amounts in turnip samples were carried out with the standard addition method. To ensure the accuracy and feasibility of the method, the optimized SWS voltammetric procedure was used directly, without any pre-treatment to samples. Consequently, the data obtained by new SWSV electrochemical method which is fast, easy, portable for the determination of antioxidants is compatible with the results of the total flavonoid content most among other spectrophotometric methods. According to all analytical methods, it has been proved that the antioxidant capacity of hot turnip juice is higher than that of normal turnip juice.

\section{REFERENCES}

1. Bartosz G. Food oxidants and antioxidants: chemical, biological, and functional properties: CRC press; 2013.

2. Algarra M, Fernandes A, Mateus N, de Freitas $\mathrm{V}$, da Silva JCE, Casado J. Anthocyanin profile and antioxidant capacity of black carrots (Daucus carota L. 
ssp. sativus var. atrorubens Alef.) from Cuevas Bajas, Spain. Journal of Food Composition and Analysis. 2014;33(1):71-6.

3. Lobo V, Patil A, Phatak A, Chandra N. Free radicals, antioxidants and functional foods: Impact on human health. Pharmacognosy reviews. 2010;4(8):118.

4. Nizamlığlu N, Nas $\mathrm{S}$. The phenolic compounds in vegetables and fruit; structures and their importance. Electronic Journal of Food Technologies. 2010;5(1):20-35.

5. Erten $\mathrm{H}$, Tanguler $\mathrm{H}$, Canbaş $\mathrm{A}$. A traditional Turkish lactic acid fermented beverage: Shalgam (Salgam). Food Reviews International. 2008;24(3):352-9.

6. Tanguler $\mathrm{H}$, Erten $\mathrm{H}$. Occurrence and growth of lactic acid bacteria species during the fermentation of shalgam (salgam), a traditional Turkish fermented beverage. LWT-Food Science and Technology. 2012;46(1):36-41.

7. Tanguler $\mathrm{H}$. Identification of predominant lactic acid bacteria isolated from shalgam beverage and improvement of its production technique. Doctor of Philosophy thesis, Cukurova University, Adana, Turkey. 2010.

8. Gläßgen WE, Wray V, Strack D, Metzger JW, Seitz HU. Anthocyanins from cell suspension cultures of Daucus carota. Phytochemistry. 1992;31(5):1593601.

9. Alasalvar C, Grigor JM, Zhang D, Quantick PC, Shahidi F. Comparison of volatiles, phenolics, sugars, antioxidant vitamins, and sensory quality of different colored carrot varieties. Journal of Agricultural and Food Chemistry. 2001;49(3):1410-6.

10. Wootton-Beard PC, Moran A, Ryan L. Stability of the total antioxidant capacity and total polyphenol content of 23 commercially available vegetable juices before and after in vitro digestion measured by FRAP, DPPH, ABTS and Folin-Ciocalteu methods. Food Research International. 2011;44(1):217-24.

11. Contreras-Calderón J, Calderón-Jaimes L, Guerra-Hernández E, García-Villanova B. Antioxidant capacity, phenolic content and vitamin $C$ in pulp, peel and seed from 24 exotic fruits from Colombia. Food research international. 2011;44(7):2047-53.

12. Shahidi F, Naczk M. Antioxidant properties of food phenolics. Phenolics in food and nutraceuticals. CRC Press; 2004.
13. Dewanto $\mathrm{V}, \mathrm{Wu} \mathrm{X}$, Adom KK, Liu RH. Thermal processing enhances the nutritional value of tomatoes by increasing total antioxidant activity. Journal of agricultural and food chemistry. 2002;50(10):3010-4.

14. Zhishen J, Mengcheng $T$, Jianming $W$. The determination of flavonoid contents in mulberry and their scavenging effects on superoxide radicals. Food chemistry. 1999;64(4):555-9.

15. Lee KW, Kim YJ, Lee HJ, Lee CY. Cocoa has more phenolic phytochemicals and a higher antioxidant capacity than teas and red wine. Journal of agricultural and food chemistry. 2003;51(25):7292-5.

16. Kumaran A. Antioxidant and free radical scavenging activity of an aqueous extract of Coleus aromaticus. Food chemistry. 2006;97(1):109-14.

17. Rai S, Wahile A, Mukherjee K, Saha BP, Mukherjee PK. Antioxidant activity of Nelumbo nucifera (sacred lotus) seeds. Journal of ethnopharmacology. 2006;104(3):322-7.

18. Apak R, Güçlü K, Özyürek M, Karademir SE. Novel total antioxidant capacity index for dietary polyphenols and vitamins $C$ and $E$, using their cupric ion reducing capability in the presence of neocuproine: CUPRAC method. Journal of agricultural and food chemistry. 2004;52(26):7970-81.

19. Demir E, Senocak A, Tassembedo-Koubangoye MF, Demirbas E, Aboul-Enein HY. Electrochemical Evaluation of the Total Antioxidant Capacity of Yam Food Samples on a Polyglycine-Glassy Carbon Modified Electrode. Current Analytical Chemistry. 2018;14:1-8.

20. Pastor FT, Šegan DM, Gorjanović SŽ, Kalušević AM, Sužnjević DŽ. Development of voltammetric methods for antioxidant activity determination based on Fe (III) reduction. Microchemical Journal. 2020;155:104721.

21. García-Carvajal E, Blandón-Naranjo L, VillaMontoya V, Vázquez MV, Peláez-Jaramillo C. Electrochemical Approach to the Study of the Antioxidant Capacity of Vaccinium Meridionale Swart at Different Ripening Stages. Portugaliae Electrochimica Acta. 2019;37(1):71-82.

22. Alcalde B, Granados M, Saurina J. Exploring the Antioxidant Features of Polyphenols by Spectroscopic and Electrochemical Methods. Antioxidants. 2019;8(11):523.

23. Giovagnoli-Vicuña C, Pizarro S, BrionesLabarca V, Delgadillo Á. A Square Wave Voltammetry Study on the Antioxidant Interaction and Effect of 
Extraction Method for Binary Fruit Mixture Extracts. Journal of Chemistry. 2019;2019.

24. de Araújo Rodrigues I, Gomes SM, Fernandes IPG, Oliveira-Brett AM. Phenolic Composition and Total Antioxidant Capacity by Electrochemical, Spectrophotometric and HPLC-EC Evaluation in Portuguese Red and White Wines. Electroanalysis. 2019;31(5):936-45.

25. Demir E. Sensitive and Selective Pathway of Total Antioxidant Capacity in Commercially Lemon, Watermelon and Mango-pineapple Cold Teas by Square Wave Adsorptive Stripping Voltammetry. Gazi University Journal of Science. 2019;32(4):1123-36.

26. Vilas-Boas Â, Valderrama P, Fontes N, Geraldo $D$, Bento F. Evaluation of total polyphenol content of wines by means of voltammetric techniques: Cyclic voltammetry vs differential pulse voltammetry. Food chemistry. 2019;276:719-25.

27. Ekinci FY, Baser GM, Özcan E, Üstündağ ÖG, Korachi M, Sofu A, et al. Characterization of chemical, biological, and antiproliferative properties of fermented black carrot juice, shalgam. European Food Research and Technology. 2016;242(8):1355-68.

28. Öztan T. Antioxidant activities and phenolic substance profile of purple carrot, its concentrate, shalgam beverage, pomegranate juice and sour pomegranate concentrate products. International Information System For The Agricultural Science And Technology (AGRIS). 2006. 